\title{
DISCURSO E BIOPOLÍTICA: O LEGISLATIVO BRASILEIRO SOBRE A VI(N)DA DE IMIGRANTES HAITIANOS
}

\section{DISCOURSE AND BIOPOLITICS: THE BRAZILIAN LEGISLATIVE ON THE ENTRANCE AND LIFE OF HAITIAN IMMIGRANTS}

\author{
Annemeire Araujo de Lima*
}

\begin{abstract}
RESUMO
O presente estudo apresenta uma análise discursivo-interpretativa fundamentada na noção de biopolítica apresentada por Michel Foucault. Seu intuito se inscreve na busca por marcas discursivas que exponham a inserção de características biológicas fundamentais à espécie humana no jogo político presente em todas as formas de relação humana e a articulação dos dispositivos de biopoder apontados por Michel Foucault como construtos de saber e de sujeitos na sociedade. As fontes dos recortes selecionados para esta análise são reportagens nas quais se manifestaram senadores preocupados com as demandas do fluxo migratório oriundo do Haiti desde 2010, ano em que o país foi vitimado por um terremoto, e nas quais também são divulgadas mudanças na legislação brasileira que, a princípio motivadas pela questão haitiana, foram aplicadas à imigração como um todo.
\end{abstract}

Palavras-Chave: Análise discursivo-interpretativa. Biopolítica. Fluxo migratório. Legislação brasileira.

\begin{abstract}
This study presents a discursive interpretative analysis based on the concept of biopolitics by Michel Foucault. It aims to search discursive marks which put the fundamental biological characteristics of human species in the political game of human relationships and the articulation of biopower devices pointed out by Michel Foucault as constructs of knowledge and subjects in society. The sources of the selected clippings for this analysis are reports on which senators expressed their concerns about migration coming from Haiti since 2010, when the country was destroyed by an earthquake, and in which are exhibited the changes in Brazilian legislation first motivated by the Haitian situation and then applied to immigration as a whole.
\end{abstract}

Keywords: Discursive interpretative analysis. Biopolitics. Migration. Brazilian legislation.

“Mestra em Estudos da Linguagem do Programa de Pós-Graduação em Letras da Universidade Federal do Amazonas. E-mail: eriemenna@live.com 


\section{INTRODUÇÃO}

\begin{abstract}
"Toda manhã na África, a gazela acorda. Ela sabe que precisa correr mais rápido que o mais rápido dos leões para sobreviver. Toda manhã um leão acorda. Ele sabe que precisa correr mais rápido que a mais lenta das gazelas senão morrerá de fome. Não importa se você é um leão ou uma gazela. Quando o sol nascer, comece a correr".
\end{abstract}

Provérbio Africano

Eu estava começando o Ensino Médio quando li esse provérbio pela primeira vez. Lembro que, além da imagem da gazela e do leão correndo, me veio à mente a triste conclusão de que isso é real, rotineiro e que um deles quase sempre perderá. Talvez por meu excesso de sensibilidade infanto-juvenil eu não pensava no equilíbrio natural que isso geraria ou sequer na felicidade da vitória do leão. Apenas encarava com pesar a perda da gazela. Em meu julgamento, o leão era aquele que nunca morre de fome, pois ele é sempre capaz de vencer a corrida. $O$ fato é que eu não ampliava o olhar para o que havia além e em volta do leão e da gazela, meu foco interpretativo era somente nos dois protagonistas do ditado. E era assim que eu ficava meditando nas aulas cujo tópico fosse ou estivesse relacionado à cadeia evolutiva da vida na selva: essa luta pela sobrevivência das espécies ou a teoria de que os mais fortes (ou mais velozes) sempre vencem.

A experiência que acabo de reportar retornou à minha memória depois de, pelo interesse em escrever este artigo e por leituras que fiz a fim de cumprir esta tarefa, ter verificado que no capítulo III do livro $A$ origem das espécies, Charles Darwin faz notar mediante seus estudos sobre a vida, que utilizaria a expressão luta pela existência. Ao optar por estes termos, o estudioso explica que os utilizaria em seu sentido geral e metafórico, pois deste modo adaptaria à sua teoria todos os sentidos que os vocábulos abarcam.

Devido a possibilidade dos vários sentidos deste termo "confundirem-se uns com os outros", o biólogo demonstra essa variedade exemplificando que, tanto dois carnívoros brigando um contra o outro por comida, quanto a planta que vive sozinha num deserto e depende da umidade para sobreviver, caracterizam a necessidade instintiva de manter-se ali e, portanto, manifestam sua persistência e esforço pela vida. Configuram, portanto, uma luta (DARWIN, 2003, p.77). Darwin ressalta ainda que "há uma relação mútua de dependência entre os seres organizados e, o que é mais importante, não é somente a vida do indivíduo como também sua aptidão e bom êxito em deixar descendentes" (DARWIN, 2003, p. 77-78).

Redirecionando nossa atenção ao provérbio que conheci na adolescência e associando sua mensagem às noções darwinianas, é possível interpretá-lo da seguinte maneira: $\mathrm{O}$ leão corre para ter o que comer, a gazela corre para não ser comida. De um ângulo, tem-se a luta por invasão ou ataque, em outro a luta por evasão ou defesa. A ação imediata desses animais é a mesma, a motivação também. O que os distingue neste cenário é a condição que os posiciona enquanto caça e caçador e futuramente como vencidos ou vencedores da corrida, ou seja, a aptidão de correr mais rápido.

Se atentarmos para o final do provérbio, veremos que existe uma clara tentativa, não somente de fazer com que quem o leia se posicione como gazela ou leão, mas também de deixar uma lição moral ao afirmar que independente dessa escolha, a luta é a mesma: manter-se vivo. Além disso, a lição revela que a condição para viver é correr. Para nós, seres humanos, entenda-se o ato correr (salvo situação muito específica) em seu sentido metafórico.

Essa necessidade de sobrevivência não torna os animais e vegetais diferentes de nós, seres humanos, mas existem características biológicas que pertencem somente a nós e, obviamente, das quais o leão e a gazela não podem usufruir. Tais características essencialmente humanas nos colocam no topo da cadeia evolutiva. Somos seres falantes. Somos seres racionais e criativos. Acontece que, com o passar dos séculos, essa criatividade nos permitiu produzir fogo, armas, guerras e tecnologias antes jamais imaginadas. Em todas as nossas relações com outros humanos e com outros seres vivos estabeleceu-se uma classificação natural e uma seleção natural de quem é líder e de quem é liderado. Essa conjuntura foi naturalmente revelando a variedade de aptidões que se não possuímos de maneira inata, adquirimos conforme nos é forçoso, por uma questão de mudança natural em nosso ambiente ou necessidade de sobreposição a outros seres.

Michel Foucault, filósofo dedicado ao estudo crítico da modernidade, comenta em seu curso intitulado Em defesa da Sociedade que "o conjunto das noções de Darwin como: a hierarquia das espécies, luta pela vida e seleção natural, tornou-se uma maneira 
de pensar as relações da colonização, das guerras e a história das sociedades em suas diferentes classes, etc" (FOUCAULT, 2005, p.307). Deste modo, se pararmos para pensar, o que descreve a rotina da vida na selva pode muito bem nos levar a um deslocamento de sentido. Saindo da questão biológica que classifica os seres vivos, seu estado evolutivo e seu comportamento na cadeia alimentar, podemos refletir a parte final do provérbio como uma tentativa pertinente de aproximar a vida humana ao cotidiano do leão ou da gazela, destacando que a espécie a qual pertencemos é indiferente à necessidade que todos nós possuímos de correr para preservar a nossa vida.

De todo um conjunto de saberes oriundos de várias épocas da história das sociedades e por meio dos quais foram se estabelecendo vários tipos de poderes e diretrizes para o modo como as pessoas devem ou não se comportar, este artigo optou por refletir a problemática da biopolítica ou biopoder, um tipo de poder definido por Michel Foucault como "um conjunto de mecanismos pelos quais aquilo que, na espécie humana, constitui suas características biológicas fundamentais vai poder entrar numa política, numa estratégia política, numa estratégia geral do poder" (FOUCAULT, 2008, p.3).

Aproximando o contexto geral das especificidades da vida em sociedade, este artigo procura mostrar quais mecanismos são utilizados como elementos da luta pela vida e de que modo eles e as características da naturalidade humana se relacionam com o meio político institucionalizado (não natural) do qual essa naturalidade faz parte. Nossa hipótese é a de que, ora como leão, ora como gazela, ora perseguindo ora sendo perseguida, essa relação vida-instituição se constrói em nome de sua permanência no mundo que rotula, classifica, hierarquiza e com isso gera um tipo qualquer de poder sobre os demais ou um tipo de comportamento sobre si mesmo.

Assim como as demais características exclusivamente humanas, a linguagem entra no jogo das interações sociais e com isso participa dessa política social. Assim, é por meio do discurso, definido por Foucault como «um conjunto de enunciados que se apoia em um mesmo sistema de formação" (FOUCAULT, 2008, p. 122), que ela indica o que é verdade ou não, o que pode ser dito e feito, como uma prática que se estabelece dentro das lutas políticas e das regras que nela surgem a partir de seus próprios critérios.

Ao pensar no jogo linguístico, este trabalho tem um viés discursivo por lidar com o discurso enquanto um desses veículos de interação nas sociedades organizadas. Foucault (1996, p. 9) problematiza a produção do discurso como "controlada e redistribuída por um número de procedimentos que têm por função conjurar seus poderes e perigos, dominar seu acontecimento aleatório, esquivar sua temível materialidade".

Por fundamentar-se nos estudos de Michel Foucault, seguiu-se as orientações foucaultianas de não levarmos o estudo ao campo da sociologia, nem ao campo da história, nem ao campo da economia e sim ao modesto intuito de analisar criticamente os efeitos de sentido de qualquer discurso que atua direta e indiretamente no modo de agir das pessoas, em seus comportamentos e tomada de decisões.

Me aproprio desta intenção e retomo, a partir do relato de minhas impressões juvenis sobre a vida animal na África, a narrativa que de certo modo me motivou a escolher o tema deste artigo:

As aulas de Biologia do Ensino Médio passaram, o tempo passou e eu me tornei professora. Certa vez, tendo concluído a minha corrida diária, já de volta para casa, entrei no ônibus e comemorei o fato de ter conseguido um lugar para sentar. Dali a alguns minutos, em um ponto qualquer do percurso entre a escola e a minha casa, embarcou no veículo uma senhora com um container de plástico nos braços. Dentro dele havia balas e chicletes postos à venda. Não fora a dificuldade que aquela senhora tinha em falar português sem um forte sotaque estrangeiro e os erros de concordância típicos de quem está aprendendo uma língua, ela seria mais uma entre alguns tantos vendedores que adentram os meios de transporte público manauara a fim de também exercer sua "corrida".

Mesmo com certa dificuldade em se fazer entender e até mesmo justificada pelo fato de não falar português muito bem, aquela senhora pediu que comprássemos balas "para ajudá-la”. Sua argumentação não podia ir longe, pois dominava muito pouco do idioma, então ficou repetindo várias vezes, com a mesma frase, que déssemos a ela uma ajuda. Ficou alguns minutos ali tentando explicar que se assim fizéssemos Deus nos ajudaria também.

O modo como ela tentava persuadir seu público, apelando para a fé dos passageiros, me levou a refletir 
sobre o óbvio: o que ela chamava de ajuda é o que todo cidadão do mundo, inclusive eu e ela, conhece por dinheiro. E o que chamamos - nós de um lado, e ela de outro - de dinheiro, nada mais é do que aquilo que, independente do nome, jamais perderá o poder que possui enquanto condição imposta a toda e qualquer pessoa que precisa comer, beber, morar e viver, ou seja, suprir suas necessidades básicas.

A busca dessa senhora, migrante do Haiti, pequeno país da América Central abalado por um terremoto em 12 de janeiro de 2010 no qual morreram pelo menos 250 mil pessoas, é uma busca comum a todos que precisam viver - independentemente se em seu país de origem ou fora dele. Esse princípio, que não é exclusivo da humanidade ou de determinadas áreas geográficas em que se vive, é imperativo a tudo o que é vivo. E oferece-nos a cada dia somente duas opções: a de viver ou a de morrer. Essa insistência biológica de viver - a partir de uma variedade das aptidões de cada um, ou a partir da persistência contra fenômenos naturais sobre os quais o homem não tem controle - atribui a existência àquela característica de luta citada pelas teorias evolucionistas mencionadas no começo deste artigo.

É essa luta travada pela população haitiana enquanto imigrante em território brasileiro o fator motivador da pesquisa aqui realizada. Mas faremos um estudo pautado sobre a análise foucaultiana de discursos proferidos por quem não faz parte desse grupo de imigrantes- embora faça parte do grupo dos que lutam. Tentaremos compreender opiniões e medidas tomadas pelo governo, divulgadas por sites autorizados pelo senado a divulgar os debates em torno das questões governamentais do Brasil.

Verificaremos o que neles está sendo representado como verdade e como norma. Refletiremos o que provoca essas opiniões; os fatores que causaram as medidas tomadas pelo Estado quanto à entrada dos haitianos no país; os interesses mobilizados por esse aparelho divulgador que é a Agência do Brasil via Empresa Brasil de Comunicação - EBC; que práticas essas medidas e opiniões incentivam.

Para começar, eis alguns questionamentos passíveis de interpretação a que esse estudo se propõe: Como se dá a construção de saber e de sujeito produzida pelo sistema legislativo brasileiro no que diz respeito à migração haitiana e posteriormente à migração como um todo? Quais mecanismos de biopolítica mencionados por Michel Foucault podem ser notados nos pronunciamentos divulgados pelas reportagens selecionadas para a análise? De que modo o que a legislação brasileira pronuncia sobre a migração haitiana e a criação de um novo estatuto da imigração se relacionam com o que fora constituído enquanto característica biológica fundamental da espécie humana?

\section{A BIOPOLÍTICA E SEUS MECANISMOS}

O ano de 2015 trouxe por meio da divulgação midiática uma realidade comovente e, por que não, revoltante: as centenas de vidas perdidas na tentativa de migrar da Síria para a Europa. As opiniões são distintas, as resoluções dificultadas, a omissão e a repressão evidentes. Temos um país em Guerra Civil e seus residentes migrando na luta contra a morte, e encontrando no caminho exatamente aquilo do que fugiam: morrem a bordo de embarcações tentando atravessar o mar Mediterrâneo. A guerra civil, como toda guerra, é uma guerra de interesses. Quanto às suas consequências tem-se os interesses e pontos de vista do governo, do público em geral e da própria população que migra e se arrisca para não perder sua família, sua dignidade e sua vida.

No que diz respeito a migração haitiana existem aspectos que a diferenciam da migração síria, embora os três pontos de vista acima mencionados também existam em seu âmbito. No que cerne o estudo que aqui se apresenta, a realidade específica dos haitianos no Brasil, teremos nossa atenção voltada para os posicionamentos e medidas do governo brasileiro em relação à essa situação. Deixa-se claro então que, por uma questão metodológica, esse seja o foco da análise.

Sendo assim, a intenção não é dizer que na prática essa separação seja possível, mas que foi necessário fazer um recorte para trazer à tona o que interessa aqui: as manifestações de um discurso que não encontra sua origem no momento em que é proferido nem se encerra por meio da linguagem, mas que se expande justamente por ser discurso e que se torna político porque constitui relações de poder, saber e sujeito em uma relação circular possível de se analisar.

Antes de nos dirigirmos ao material de análise importa reforçar o que é a biopolítica (ou biopoder) e os mecanismos que assumem com ela uma nova forma de organizar, construir e sobreviver em sociedade. 
Nosso arcabouço teórico traz Michel Foucault e suas contribuições quando entende que "o intuito do poder, presente intrinsecamente em todas as relações de produção e vida em sociedade é manter-se" (FOUCAULT, 2008, p.4). Para o filósofo, este poder não se mantém em si mesmo haja vista está presente em cada relação, em todas elas, é efeito e causa delas e mesmo manifestando-se em forma de hierarquia, analogias técnicas, "não passa de táticas que surgem em meio a lutas sociais e produzem efeitos de saber para suscitar o que pode ser feito, dito, de quem para quem, em que lugar ou circunstância" (FOUCAULT, 1996,p. 35-37).

Michel Foucault frisa que uma análise não deve ser política partidária, mas filosófica. Isso se diz no sentido de que, segundo o autor, "cabe à Filosofia essa relação séria e fundamental entre a luta e a verdade"(FOUCAULT, 2008, p.5).

Tais orientações nos alertam sob a justificativa de que ater-se nas polêmicas internas ao discurso teórico faz com que essa relação entre a luta e a verdade perca o sentido e que, por essa razão, não se trata de definir partidos e ideologias partidárias, mas entender como se dão essas relações e de que modo em seu interior temos a linguagem e o discurso participando de sua produção de sentidos.

Sendo "o conjunto de procedimentos que levaram a sociedade ocidental moderna a, a partir do século XVIII, voltar a levar em conta o fato biológico fundamental de que o ser humano constitui uma espécie humana" (FOUCAULT 2008, p.3), o biopoder possui mecanismos classificados em três tipos ou formas: a primeira seria $a$ lei, o sistema do código legal que diz o que é proibido e o que é permitido. A segunda seria $a$ disciplina, técnicas que vão desde o suplício a prisão, a punição institucionalizada a quem infringe a lei. A terceira seria a mais próxima da contemporaneidade, mesmo que já estivesse implícita em épocas nas quais os outros dois eram predominantes: o dispositivo de segurança, que vai relacionar o fenômeno irregular a uma série de acontecimentos prováveis a fim de não somente tratar do que é permitido e proibido, mas de calcular custos, limites do que se pode relevar e do que não se pode a fim de evitar riscos presentes e futuros. O que não exime a lei e a disciplina de participação.

Partindo de tais leituras, a concepção foucaultiana chegará à conclusão de que os três mecanismos - lei, disciplina e segurança - estão inter-relacionados mesmo quando um se sobrepunha e era mais frequente do que outro, mesmo que cada época na história da humanidade tenha se notado a presença maior de um ou de outro. Foucault esclarece que existe uma linha do tempo na qual cada um dos mecanismos se constituiu, mas enfatiza que sua atuação nas sociedades é atemporal. Em suma, o que se tem é que a segurança "é uma certa maneira de acrescentar, de fazer funcionar as velhas estruturas da lei e da disciplina" (FOUCAULT, 2008, p.10-14).

Cada mecanismo de biopoder tem suas características que adquirem visibilidade pelos embates que surgem em todas as formas de relação humana. Ao expressar-se de determinado lugar para um público específico gera-se um discurso também determinado por essas condições e por fatores precedentes que o construíram e melhoraram de acordo com as novas realidades que vinham surgindo. Sendo assim, o que se demonstrará não diz respeito somente ao hoje e a uma relação específica, mas traz em si reflexos de outras realidades e outras relações.

$\mathrm{Na}$ medida que formos comentando os dados, exporemos tais características e tentaremos explicitar a questão discursiva que levanta o poder legislativo quando questiona a situação dos haitianos e impõe sobre ela uma normalização em forma de estatuto que passará a reger a vida destes e de imigrantes de outras nacionalidades.

\section{A SITUAÇÃO DOS HAITIANOS NO BRASIL}

\author{
"Não há maior dor no mundo que a \\ perda de sua terra natal". \\ Eurípedes, 431 a.C.
}

A citação acima foi retirada de um blog chamado "Haitianos no Brasil", que dentre outros se interessa pela situação dos haitianos e acompanham como ela tem sido tratada ou vivida. Para contextualizar a situação desses imigrantes, utilizaremos algumas pesquisas realizadas em 2013 por equipes de pesquisas do governo federal e do Conselho Nacional de Imigração (CNIg), Ministério do Trabalho e Emprego do Brasil, e a Organização Internacional para a Migração (OIM).

Nota-se que tais levantamentos tiveram o intuito de saber quem são esses imigrantes, os motivos que os trouxeram ao Brasil, as dificuldades no trajeto e no 
destino bem como algumas iniciativas governamentais tomadas para amenizar os transtornos bilaterais deste fenômeno migratório. Mesmo com o cuidado de contextualizar a que realidade os sujeitos se referem, é necessário deixar claro que, embora separado dos pronunciamentos, esse contexto está impregnado neles. E não separado.

A Secretaria de Direitos Humanos do governo federal enviou uma equipe que aplicou questionário aos migrantes haitianos no Acre para conhecer um pouco do seu perfil e de sua realidade desde a saída de seu país até a chegada e permanência no Brasil. Foram aplicados 412 questionários a 412 haitianos presentes no abrigo de Brasiléia-Acre entre 30/10 e 02/11 de 2013.

A pesquisa demonstrou que a maioria dos imigrantes entrevistados era do sexo masculino, de religião evangélica e falantes de crioulo e francês. Além disso que não possuíam o ensino fundamental completo e que demonstravam interesse em participar de cursos profissionalizantes.

Dentre as rotas de entrada no Brasil, a maioria dos entrevistados diz que saiu do Haiti e entrou pela República Dominicana, Panamá, Equador e Peru, gastando até 4 mil dólares nesta viagem feita em geral sozinhos e que segundo eles dura entre uma e três semanas.

Os haitianos entrevistados relatam que sofreram extorsão e roubo no decorrer de sua viagem e que permaneciam no abrigo no Acre porque aguardavam oportunidade de emprego e emissão de documentos. Quando questionados sobre para onde iriam depois que os documentos saíssem, eles em sua maioria disseram que não sabiam e outros mencionaram São Paulo e Santa Catarina como possíveis destinos dentro do país. As mulheres tinham entre 18 e 30 anos e das 412 pessoas entrevistadas, 06 eram crianças.

Em parceria com as instituições que acolheram os imigrantes em Rondônia, Minas Gerais e Paraná, outra pesquisa de levantamento foi realizada e apresentou com mais detalhes as motivações dos haitianos, as dificuldades encontradas no Brasil, o acesso aos serviços públicos básicos e suas sugestões ao governo brasileiro e haitiano quanto ao apoio à sua migração.

Essa segunda pesquisa demonstra que as três maiores motivações para a vinda dos haitianos são: trabalho, melhor qualidade de vida e ajudar a família. E que nem todos tinham um plano de viagem ou destino definido. Exemplifica que, alguns saíram do Haiti em direção aos Estados Unidos, mas encontraram dificuldades e desviaram sua rota para outros países.

Uma das limitações mais citadas depois da chegada no Brasil é a dificuldade em falar português e o acesso a moradia em razão da falta de confiança de proprietários de imóveis em alugar esses lugares aos haitianos e o fato de eles terem de compartilhar do mesmo espaço quando percebem que morar junto a outros é menos oneroso.

Além dessa dificuldade, posterior àquela de se tirar os documentos e vistos, os entrevistados afirmar ser difícil encontrar emprego. Boa parte deles atua na construção civil e reclamam de autoritarismo e salário baixo. Na questão da educação, os haitianos elogiam as escolas públicas porque dão alimentação e material escolar de graça e solicitam mais oportunidades de ensino superior. Daqueles que concluíram o Ensino Médio, alguns são participantes do programa FIES e já fazem faculdade em algumas instituições de ensino privadas.

Quanto à saúde, os imigrantes comentam terem sido bem tratados e mesmo quando foram ao hospital sem carteira do SUS foram atendidos e receberam medicamentos de graça. Em alguns estados como Rondônia e Minas Gerais, os imigrantes relataram pouca eficiência nos exames e indiferença nos hospitais. Dizendo que nas Unidades Básicas de Saúde o atendimento é um pouco melhor. As mulheres manifestam preocupação com gravidez e AIDS, deixando claro que são casadas e utilizam preservativos para evitar a gravidez.

Descrever com o auxílio dessas pesquisas oficiais e seus resultados a situação dos haitianos no Brasil foi um fator que se fez necessário por se considerar que a articulação política surge de um contexto, uma necessidade. É a partir destes fatores que temos então envolvidos no caso da imigração, os saberes geográficos, psicológicos, educacionais, jurídicos, etc.

É também por meio de um acontecimento dado que verificamos a possibilidade de insurgência de um saber e de um poder, pois segundo Foucault apud Bruni (1989) o processo de sujeição humana se dá em forma de estigmatização, marginalização, patologização e confinamento, e suas ferramentas podem ser traduzidas nas instituições sociais como a família, o aparelho judiciário, o saber médico. 


\section{A “METODOLOGIA" FOUCAULTIANA E O CORPUS DE ANÁLISE}

Por entender o homem como objeto de poderes e de instituições, Michel Foucault desprivilegia o domínio humano sobre o objeto estudado e nos apresenta uma produção teórica e metodológica que procura evidenciar como a sociedade atual funciona a partir do processo de sujeição humana através da história.

Em consequência de termos escolhido esta perspectiva, as formações discursivas constitutivas dos textos em análise ganham nossa atenção por constituírem-se de acordo com um descontínuo movimento histórico e serem passíveis de mudanças, por sua vez, também sofridas pelo método de abordar aquelas formações e pelo sujeito que o utiliza.

Semelhante ao estudo antropológico, onde os pormenores não são tomados como variáveis independentes e sim em sua relação comum com o todo, Foucault propõe uma atenção especial ao poder enquanto elemento variável nessas relações:

fazer uma análise ascendente do poder, ou seja, a partir dos mecanismos infinitesimais, os quais tem sua própria história, seu próprio trajeto, sua própria técnica e tática, e depois ver como esses mecanismos de poder, que têm, pois, sua solidez e, de certo modo, sua tecnologia própria, foram e ainda são investidos, colonizados, utilizados, inflectidos, transformados, deslocados, estendidos, etc., por mecanismos cada vez mais gerais e por formas de dominação global (FOUCAULT, 2005, p. 36).

Essa intenção do autor nos revela que ele procurava compreender o que torna possível e impossível que textos generalizem e prescrevam o modo como o homem tem que se comportar e viver quando, na realidade, a vida se faz "de experiências de estados mistos, polimórficos, heterogêneos, contingenciais, em sequências históricas regionalmente delimitadas, numa geografia analítica do local" (NETO, 2015, p. 417).

Compreender esse mecanismo discursivo significa compreender que o sujeito se constitui pela linguagem, e que por ela é que se faz a opressão ou a liberdade. Fischer corrobora a epistemologia de Foucault ao defender que

é necessário, no mundo da pesquisa, fugir das explicações de ordem ideológica, das teorias conspiratórias da história, de explicações mecanicistas de todo tipo e dar-se conta de como nos tornamos sujeitos de certos discursos, de como certas verdades se tornam naturais, hegemônicas, especialmente de como certas verdades se transformam em verdades para cada sujeito, a partir de práticas mínimas, de ínfimos enunciados, de cotidianas e institucionalizadas regras, normas e exercícios (FISCHER, 2003, p. 385).

Este estudo entende que lidar com o processo de sujeição humana - visível nos ditos e não ditos dos textos - requer renúncia aos métodos de pesquisa tomados como definitivos e considera o registro documental como fonte de reflexão.

\section{A FONTE}

A Empresa Brasil de Comunicação (EBC, 2018) é um sistema de radiodifusão criado em 2007 para fortalecer o sistema público de comunicação. É gestora dos canais TV Brasil, TV Brasil Internacional, Agência Brasil, Rádio Agência Nacional e do sistema público de Rádio - composto por oito emissoras. Estes, por sua independência editorial, distinguem-se dos canais estatais ou governamentais, com conteúdo diferenciado e complementar aos canais privados.

Sua criação tem como missão prover um sistema público de comunicação que busque complementar o sistema privado, dando-lhe mais pluralidade, assegurando espaços para os que não têm acesso às grandes redes, seja para exprimir opiniões ou para veicular suas produções.

\section{A ESCOLHA}

O critério para a escolha do corpus de análise se deu a partir do caráter discursivo que ele apresenta. Considerou-se que os pronunciamentos poderiam ilustrar a teoria de biopolítica apresentada por Michel Foucault quando, vinculados a um acontecimento social e político atual, possibilitaram interpretações e com elas uma produção de saber jurídico que nasce de uma preocupação com a qualidade de vida dos imigrantes (o Estado enquanto pastor preocupado com suas ovelhas) e de argumentos fundamentados no indivíduo "como efeito e objeto de poder, como efeito e objeto de saber" (FOUCAULT, 1999, p.216).

Algumas reportagens expõem a preocupação dos senadores com a situação dos haitianos e que de toda forma exigem do Estado uma providência quanto 
a isso. O papel de sujeito que eles ocupam é de legisladores, e por isso percebemos em sua fala a presença persistente de termos jurídicos, índices numéricos e exigências de ações governamentais que deem conta desses números, dessa contingência cada vez maior de imigrantes e principalmente das suas necessidades básicas: segurança, moradia, alimentação, saúde, etc.

Retiramos dos pronunciamentos (na íntegra em anexos) as falas que manifestam a urgência de uma questão jurídica e que justificativas são utilizadas para isso:

[...] inicialmente, 456 haitianos chegaram a Tabatinga (AM) em 2010. Em 2011, outros 1.898 entraram no país pelo município. E, acrescentou, apenas no primeiro mês de 2012, outros 1.460 aportaram na cidade. Desde que a resolução que concedeu visto humanitário foi publicada, em 13 de janeiro, outros 347 chegaram, mas estão em um impasse jurídico. (2012)

Com boa gestão, nosso abrigo tem capacidade para atender 150 pessoas. O abrigo já chegou a ter mais de 1,1 mil pessoas. Impossivel fazer um atendimento adequado com 1,1 mil pessoas em um abrigo com capacidade para, no máximo, 150. Temos de fazer muitos reparos e adequações para um atendimento mais adequado. (2015)

Tabatinga se transformou no limbo dos haitianos. Coiotes financiam imigrantes e cobram altos juros, inclusive detendo familiares para poderem cobrar a dívida. (2012)

[...] 4.500 haitianos que ainda estão no Amazonas, principalmente em Manaus, alguns "mendigando e pedindo esmolas nas ruas" (2012)

[...] encontrar uma maneira de fecharmos a entra$d a$, que é perigosa, ilegal e injusta, porque explora o ser humano, e não permitirmos que ocorra a exploração dessas pessoas (2015)

Quando eles chegam ao Acre, pelo menos têm um endereço e um local para comer. E quando chegam a São Paulo? E quando chegam a outros lugares? Eles têm um endereço? Será que todos são acolhidos bem? (2015)

A Resolução Normativa 97/2012 do Conselho de Migração criou o visto por razões humanitárias para os haitianos, mas apenas 1.200 podem ser emitidos por ano. Mas cada visto pode incluir familiares do beneficiado (2015).

\section{A ANÁLISE}

\section{A SEGURANÇA E A DISCIPLINA COMO PRESSUPOSTOS PARA A LEI}

Temos acima um conjunto de falas de senadores brasileiros que ocupam a função de representantes do Congresso e possuem a responsabilidade de criar e alterar leis federais, fiscalizar gastos do Poder Executivo. A posição que as pessoas detentoras da palavra e da opinião nessas reportagens é uma óbvia posição de poder.

A primeira impressão que temos de suas falas é uma crítica, apelo ou alerta a respeito dos ilegais, dos impasses jurídicos, problemas comuns na fronteira, aumento no número, problema de lei. Apontando ser necessário um posicionamento mais humanitário, por meio de vistos, atenção ao tráfico, o que demonstra o incômodo dos números de imigrantes que só crescem. Em suma, fica explícita a situação dos imigrantes como um fenômeno que trouxe problemas carentes de medidas interventivas e que o legislativo exige do executivo uma medida para isso. É isso que se tem como verdade. Todas as questões colocadas pelos participantes das reportagens revelam uma questão humanitária que demanda providências tanto no sentido de fechar a entrada, reduzir vistos, punir coiotes, dar estrutura às cidades que acolhem os imigrantes quanto abrir resoluções que documentem e forcem da parte de todos os envolvidos uma obrigação para com o governo. É isso que se tem como medida, ou norma.

Todas as providências exigidas trazem como razão a vida e a qualidade de vida por meio da segurança em primeiro plano. Ou seja, manifesta-se essa troca do organizar para dar aos imigrantes uma vida digna. Essa é uma das características do biopoder.

Dentre os mecanismos que utiliza estão, como já dissemos, o de caráter legal, o de caráter disciplinar e o de nível de segurança. A forma como esses mecanismos relacionam-se vai possibilitar ao governo a ordem, a emancipação política e a relação internacional que, segundo seus representantes, podem trazer benefícios futuros ao país. Esse interesse movimenta o ciclo do bem comum sob o comando de um soberano. E é isso o que temos no segundo plano do discurso dos senadores. 
Lembrando que, segundo uma das reportagens, o Congresso define irregular como aquele que não tem entrada criminal e sim carece de uma classificação regulamentar e normativa que somente a lei pode dar a ele, estabelece-se como técnica de controle para a entrada dos imigrantes um exame, que Michel Foucault em outro momento descreveu como uma classificação ou qualificação e isso ocorreu com o fim de estabelecer sanções que normalizem sua presença, sua entrada, sua existência no Brasil. Tem-se então a avaliação da situação dos haitianos por meio de pesquisas, resoluções para a documentação dos imigrantes, que - de acordo com a segunda reportagem (MELO; CARDOSO, 2015) - os tornam dependentes das ações governamentais para prosseguir sua viagem, a denúncia de atividade ilícita e criminosa dos coiotes.

Com o passar do tempo as pesquisas e censos acusam o aumento em número de imigrantes que continuou a ingressar no Brasil, e cinco anos mais tarde, em 2015, temos a discussão acerca da legislação:

A nossa legislação ainda é do tempo da ditadura militar [de 1980], com um caráter muito mais regulatório. A nova lei que está se discutindo tem um viés muito mais humanitário.

A chamada Lei das Migrações foi desenvolvida junto a especialistas desde 2013, em um esforço do Ministério da Justiça para trazer um outro olhar para uma realidade presente e que demanda regulamentação.

Não podemos tratar as vítimas como vilões. Agora, que se cumpra a lei e se punam os verdadeiros criminosos.

Para o Palácio do Planalto, lidar com os imigrantes pode dar a projeção internacional que o País vem buscando há anos.

A Comissão de Relações Exteriores e Defesa Nacional do Senado aprovou hoje (2) o projeto que institui a nova Lei de Migração.

[...] o texto muda a interpretação brasileira relacionada ao tratamento dado às pessoas de outros países que queiram viver no Brasil, com a mudança do termo "estrangeiro", em vigor desde a época da ditadura militar, para 'migrante'.

Os migrantes, segundo o projeto, terão acesso igualitário e livre aos serviços, programas e benefícios sociais, bens públicos, educação, assistência jurídica integral pública, trabalho, moradia, serviço bancário e seguridade social.
As reportagens acima tratam da divulgação de uma iniciativa do governo que parte da realidade problemática dos haitianos mostrada no primeiro recorte. Essa iniciativa representa uma resposta àquela realidade e uma mudança ao que se tinha estabelecido até então. Eis aí a reconstrução do saber jurídico. A lei busca um equilíbrio em torno do que parecia estar sem controle. Reflexões foucaultianas nos indicam que "o papel dessas medidas é medir em termos quantitativos e hierarquizar em termos de valor as capacidades, o nível, a 'natureza' dos indivíduos" (FOUCAULT, 1999, p. 207).

A lei vem como:

um conjunto de textos que é preciso memorizar, não diferenciando indivíduos, mas especificando atos num certo número de categorias gerais; não hierarquizando mas fazendo funcionar pura e simplesmente a oposição binária do permitido e do proibido; não homogeneizando, com fim de realizar a partilha, adquirida de uma vez por todas, da condenação" (FOUCAULT, 1999, p.208).

Os coiotes representavam esse movimento desarticulado dos haitianos rumo ao Brasil e uma maneira de frear essa entrada era, segundo os senadores, investigar e agir contra sua ação. Ao repensar a lei de 1980, o Congresso retoma seu poder de diferenciar o lícito do ilícito neste âmbito e partindo de uma situação específica que envolve o global da problemática em um único acontecimento. Com isso, ele individualiza um fenômeno coletivo e separa vítimas de vilões com uma estratégia que, amparada na legislação, insere os indivíduos numa normalização em favor de suas próprias vidas.

Um outro ponto a se comentar é a mudança do termo "estrangeiro" para o termo "migrante", isso gera um saber linguageiro que refletirá no cotidiano das pessoas. Distinguir terminologicamente é provocar - pela mudança de um termo na lei - a mudança de comportamento da sociedade. Muito embora isso não garanta a mudança de seu pensamento, que - quando não pode se expressar explícita e verbalmente contra a lei - fica interditado.

A relação entre o modo como chamar o migrante e a sua luta pela sobrevivência é estabelecida quando se reflete que tirar a vida não necessariamente precisa ser pelo assassinato de forma direta, mas conforme pensa Foucault (2005, p. 306), ser “pura e simplesmente a morte política, a expulsão, a rejeição, 
etc". Esse direito à vida inclui também a emancipação trabalhista e direitos iguais assegurados pela nova legislação, conforme é divulgado em uma das reportagens.

\section{CONSIDERAÇÕES FINAIS}

Viver e sobreviver em sociedade exige uma organização, pois viver é ter o que comer, o que beber, onde morar e apresentar condições de superar o que possa ser ameaça a essa existência ou a reprodução dela. Imagine que quando unidos em sociedade os homens se dão conta não só da multiplicidade de suas aptidões como também de seus interesses individuais. Muitas vezes esses interesses põem em risco o interesse comum e acabam se tornando uma porta de entrada a medidas que a priori se justificam por ele, mas - quando sob uma análise mais atenta - observa-se que se tornaram técnicas de manter nas mãos de um grupo a competência de impor a população.

É justo que se fale de política por serem os sujeitos de discurso ocupantes de uma posição de autoridade estatal, no entanto lembremos que essa análise não se faz sobre esse viés e sim sobre a política presente em todas as relações humanas, inclusive na relação Poder Legislativo e cidadãos. Vejamos os senadores como detentores de um saber, de um poder e de uma subjetividade que torna suas opiniões e determinações em debate e que quase sempre levam à projetos de lei que exercem sobre a vida da sociedade geral uma consequência. Pensando assim, e unindo essa reflexão ao que foi dito em trechos de seus pronunciamentos, chegamos à conclusão que essas posições se inscrevem em uma formação ideológica. A formação ideológica é essa posição e a situação em que os senadores se encontram.

Como exemplos de como essas formações ideológicas se deixam notar ou também não são percebidas senão quando construto de sentidos a partir de determinadas condições sociais e históricas, notamos entre as medidas mais recentes, que o interesse em criar uma nova lei começa a aparecer na linguagem utilizada por seus usuários e com ele começam a aparecer também as formações discursivas. As formações discursivas fazem referência às formações ideológicas de seus falantes. Sujeitos dotados de uma autoridade e que se utilizam de seu poder argumentativo e dos recursos midiáticos para exercer seu papel.
Fazer uma análise discursivo-interpretativa nos proporciona essa visualização que nos passa desapercebida e nos convence muitas vezes de que somos sujeitos de nós mesmos.

Compreender os modos como a sociedade funciona nos mostra que nossos discursos não são inéditos, que nossas ações não são conduzidas por um caráter puramente natural, como se tivéssemos nascido com as capacidades necessárias a nos manter de pé. Essa compreensão nos leva a refletir o quanto nossas aptidões naturais são reforçadas por valores que controlam e influenciam nosso agir, pensar e falar.

Uma outra maneira de pensar e agir se impõe a partir daqui. Descobrimos que essas características de nossa natureza lançam-se num salto além do que nós mesmos podíamos supor. $\mathrm{E}$, de repente, não somos mais tão originalmente constituídos por aquilo que nos é inato, mas principalmente pelos avulsos que se afixaram nessa carga naturalmente imposta, e com ela nos tornaram parte de um jogo de sentido constituído não só pelo que ocasionou esse acréscimo ao que nós éramos, mas por todo esse conjunto integrado do que passamos a ser.

O que se nota é que esses papéis e posições que assumimos nos cobram o dever de tomar decisões mediante aos desafios e lutar por nossa permanência nessa posição, embora isso nos custe um discurso perpassado por interesses que não são somente nossos e justificados igualmente por se tratar de uma realidade que parece não ser a nossa.

Vemos, portanto, em articulação a lei, a disciplina e a segurança como dispositivos de um poder que no saber contemporâneo se interessa pela vida e pelo que traz menos gastos e custos, pela projeção internacional e os assentos na ONU, por um humanitarismo que justifica ações cujas origens permanecem inalteradas. Os mecanismos originários e originados dessa luta de poder em nome da vida fazem o que podem para manter-se ali, como todo o mais que também procura manter-se. E se organizam para esse fim.

Com o passar dos séculos, os poderes, os saberes e os sujeitos foram se adaptando ao que era novo, atribuindo a ele a justificativa da mudança, mas essa mudança parece de fato só ter ocorrido por uma questão de tentativa de recusar contextos mais amplos que, de todo modo, sobrevivem ao que se acredita ser a única verdade, a única saída ou a última corrida em uma dada conjuntura. 


\section{REFERÊNCIAS}

ARAÚJO, Thiago de. Nova lei para imigrantes coloca Brasil na vanguarda no debate sobre fluxos migratórios do mundo. Huffpost Brasil, 03 jun. 2015. Disponível em: < https://www. huffpostbrasil.com/2015/06/03/nova-lei-para-imigrantescoloca-brasil-na-vanguarda-no-debate-so_a_21681815/> . Acesso em 3 jun. 2015

BRASIL. Secretaria dos Direitos Humanos. Resultado da aplicação do questionário sobre a situação dos migrantes ou solicitantes de refúgio no abrigo de Brasileia/Acre; Instituto Migração e Direitos Humanos. Disponível em: http://www. migrante.org.br/migrante. Acesso em 08 de agosto de 2015.

BRASIL. Senado Federal; Comissão de direitos humanos e legislação participativa. A situação dos haitianos no Brasil. Disponível em: <https://www12.senado.gov.br/ecidadania> Acesso em: 22 de julho de 2015.

BRUNI, José Carlos. Foucault, o silêncio dos sujeitos. Tempo Social; Rev. Social, USP, São Paulo, v. 1, n. 1, 1989, p. 199 - 207.

DARWIN, Charles. A Origem das Espécies - no meio da seleção natural ou a luta pela existência na natureza, 1 vol., tradução do doutor Mesquita Paul. LELLO \& IRMÃO EDITORES - PORTO, 2003.

EBC. EMPRESA BRASIL DE COMUNICAÇÕES. Sobre $a$ $E B C$. Brasília: EBC, 2018. Disponível em: <http://www.ebc. com.br/sobre-a-ebc/o-que-e-a-ebc>. Acesso em 2018.

FERREIRA NETO, João Leite. Pesquisa e Metodologia em Michel Foucault. Psicologia: Teoria e Pesquisa. Jul-Set 2015, Vol. 31 n. 3, pp. 411-420.

FISCHER, Rosa Maria Bueno. Foucault revoluciona a pesquisa em educação? Perspectiva. Florianópolis, v. 21, n. 2, 2003, p. 371-389.

FOUCAULT, Michel. A Ordem do Discurso. 10. Ed. São Paulo: Edições Loyola, 2004.

FOUCAULT, Michel. Em defesa da sociedade: curso no Collège de France (1975-1976). São Paulo: Martins Fontes, 2005.

FOUCAULT, Michel. Segurança, Território, População. São Paulo: Martins Fontes, 2008.

FOUCAULT, Michel. Vigiar e Punir: nascimento da prisão. Trad. Lígia M. Ponde Vassalo. Petrópolis: Vozes, 1999.

FRANCISCO, Wagner de Cerqueira e. O terremoto no Haiti; Brasil Escola. Disponível em: https://www.brasilescola.com/ geografia/o-terremoto-no-haiti.htm. Acesso em 13 de jul. 2015.

MELO, Karine; CARDOSO, Armando. Senador do Acre pede providências para frear imigração ilegal de haitianos. Empresa Brasil de Comunicações. Brasília: EBC, 3 ago. 2015. Disponível em: <http://www.ebc.com.br/noticias/2015/08/ senador-do-acre-pede-providencias-para-frear-imigracaoilegal-de-haitianos>. Acesso em ago. 2018.

RICHARD, Ivan. Comissão do Senado aprova lei que atualiza Estatuto do Estrangeiro. Empresa Brasil de Comunicações. Brasília: EBC, 02. jul. 2015. Disponível em: $<$ http://agenciabrasil.ebc.com.br/politica/noticia/2015-07/ senado-aprova-lei-de-migracao-que-reve-legislacao-daepoca-da-ditadura>. Acesso em ago. 2015.

VAZ, Roberto. Senadores pedem pressa ao governo para tirar imigrantes haitianos do 'limbo'. Ac 24 horas. Rio Branco: AC24horas, 13 fev. 2012. Disponível em: <https:// www.ac24horas.com/2012/02/13/senadores-pedem-pressaao-governo-para-tirar-imigrantes-haitianos-do-limbo/> . Acesso em ago. 2018. 